\title{
Simulation of Stresses during Casting of Binary Magnesium-Aluminum Alloys
}

\begin{abstract}
M.G. POKORNY, C.A. MONROE, C. BECKERMANN, Z. ZHEN, and N. HORT
A viscoplastic stress model is used to predict contraction forces measured during casting of two binary $\mathrm{Mg}$-Al alloys. Force measurements from castings that did not hot tear, together with estimates from data found in the literature, are used to obtain the high-temperature mechanical properties needed in the stress model. In the absence of hot tearing, the simulation results show reasonably good agreement with the measurements. It is found that coherency of the semisolid mush starts at a solid fraction of about 0.5 and that the maximum tensile strength for the Mg-1 and $9 \mathrm{wt}$ pet $\mathrm{Al}$ alloys at their final solidification temperatures is 1.5 and $4 \mathrm{MPa}$, respectively. In the presence of hot tearing, the measured stresses are generally overpredicted, which is attributed to the lack of a fracture model for the mush. Based on the comparison of measured and predicted stresses, it is also shown that coupling of the stress model to feeding flow and macrosegregation calculations is needed in order to accurately predict stresses in the presence of hot tearing.
\end{abstract}

DOI: $10.1007 / \mathrm{s} 11661-010-0367-3$

(C) The Minerals, Metals \& Materials Society and ASM International 2010

\section{INTRODUCTION}

DURING the past decade, advanced stress models have been developed to simulate the deformations occurring during casting of metal alloys and to ultimately predict the occurrence of hot tears (for example, References 1 through 5). In these models, the semisolid mush is treated as a viscoplastic, compressible porous medium, where the mechanical behavior depends on the local volume fraction of solid among other factors. ${ }^{[6]}$ Such modeling requires the knowledge of the mechanical properties of a metal alloy over the entire range of temperatures and strain rates encountered during casting. In this regard, the coherency and strength properties of the mush, including coalescence of the solid over a certain range of solid fractions, are particularly important.

Measurements of the relevant mechanical properties of metal alloys in the semisolid state are relatively limited. ${ }^{[7]}$ Tests in which specimens are reheated and partially remelted suffer from the fact that the microstructure and the solid fraction-temperature relationship are generally not the same as during solidification from the melt. Most progress in determining the mechanical properties needed in advanced stress models has been made for aluminum alloys. ${ }^{[6-8]}$ Recently, Mathier and co-workers ${ }^{[9,10]}$ performed a detailed comparison between measured and predicted forces in the

M.G. POKORNY and C.A. MONROE, Graduate Research Assistants, and C. BECKERMANN, Professor, are with the Department of Mechanical and Industrial Engineering, University of Iowa, Iowa City, IA 52242. Contact e-mail: becker@engineering.uiowa.edu Z. ZHEN and N. HORT, Researchers, are with the Magnesium Innovation Center-MagIC, GKSS Research Center, Geesthacht, Germany.

Manuscript submitted March 9, 2010.

Article published online July 15, 2010 mush during solidification of dilute aluminum alloys. These comparisons showed that advanced stress models are able to predict the variation of the tensile stress with strain and solid fraction until fracture. Considerable insight into the coherency properties of the mush was obtained. The strength of the mush was found to increase gradually for solid fractions between 0.5 and 0.9 . Above a solid fraction of 0.9 , the strength increased more rapidly because the grains start to coalesce and form a coherent solid network. At such high solid fractions, liquid feeding is no longer possible and fracture of the mush will lead to the formation of an open hot tear.

The availability of mechanical properties that are suitable for advanced stress modeling is even more limited for magnesium alloys. Recently, an attempt has been made to numerically simulate the deformations and stresses during permanent mold casting of an AZ91 magnesium alloy in order to predict hot tears. ${ }^{[4]}$ This study relied on crude estimates of the mechanical properties. $\mathrm{Hu}$ et al. ${ }^{[11]}$ reported measurements of the constitutive behavior of an AZ31 magnesium alloy in the semisolid stage. As-cast specimens were reheated and pulled in a Gleeble machine. $\mathrm{Hu}$ et al. obtained a relation for the maximum tensile stress as a function of temperature. The maximum stress at the solidus temperature of the AZ31 alloy was measured to be $13 \mathrm{MPa}$. For higher temperatures, the ductility and strength of the semisolid alloy were found to continually decrease. The ductility reached essentially zero at a solid fraction of 0.95 , whereas the strength decreased to zero at a solid fraction of 0.87 . While these data provide a first insight into the constitutive behavior of a magnesium alloy during solidification, it is not sufficient for advanced stress modeling. The situation is worse for magnesium alloys compared to aluminum alloys, because the mechanical properties are not even well established for 
temperatures below the solidification range. Measurements of mechanical properties where the specimens were heat treated or contained porosity (e.g., die-cast specimens) must be excluded. Some studies have been identified that report suitable measurements of mechanical properties of as-cast magnesium alloys at room and elevated temperatures. ${ }^{[12-20]}$ However, the data in References 12 through 20 are also not sufficient for stress modeling of casting.

In this study, force measurements from specially designed casting experiments are used to calibrate a viscoplastic constitutive model for $\mathrm{Mg}-\mathrm{Al}$ alloys. In the experiments, measurements are performed of the evolution of the temperature and the contraction force during solidification and cooling of a restrained rod-shaped casting in a steel mold. Experiments are conducted for two binary magnesium alloys and several initial mold temperatures. The experiments are then simulated in order to predict the measured temperatures and forces. The stress simulations use, as much as possible, mechanical property data extracted from References 12 through 20. The initial yield stress (at zero viscoplastic strain and strain rate) variation of the magnesium alloys at temperatures above $573 \mathrm{~K}\left(300{ }^{\circ} \mathrm{C}\right)$ is determined by matching measured and predicted contraction forces during experiments where the casting did not hot tear. The calibrated model is then applied to experiments where hot tears were observed.

\section{EXPERIMENTS}

A schematic of the experimental test setup is shown in Figure 1. The casting consists of a $148 \mathrm{~mm}$ long horizontal rod with a vertical sprue on one end through which the molten metal is poured. The diameter of the

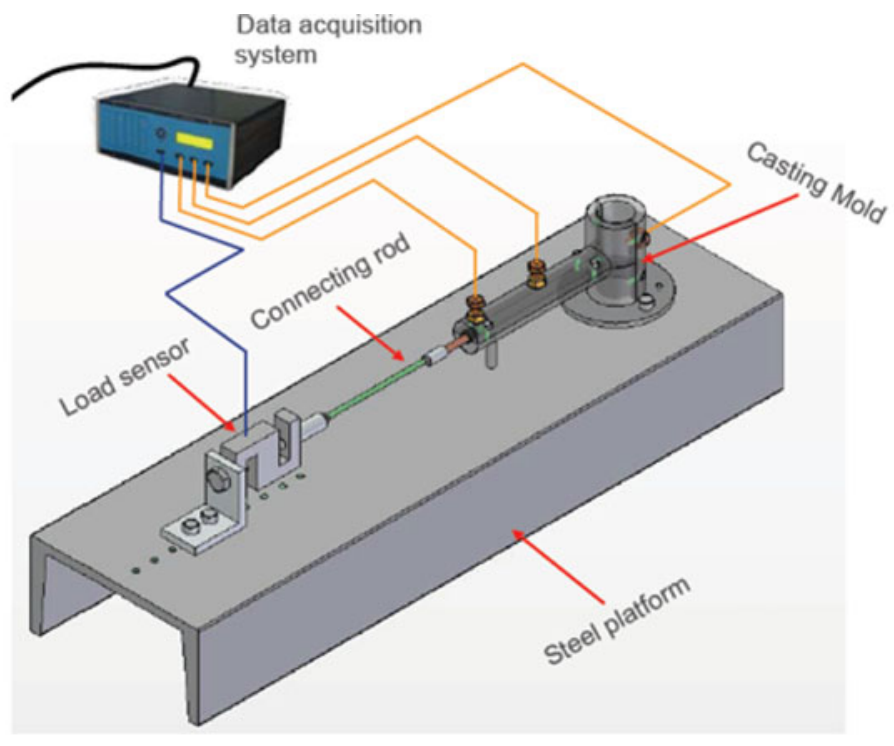

(a)
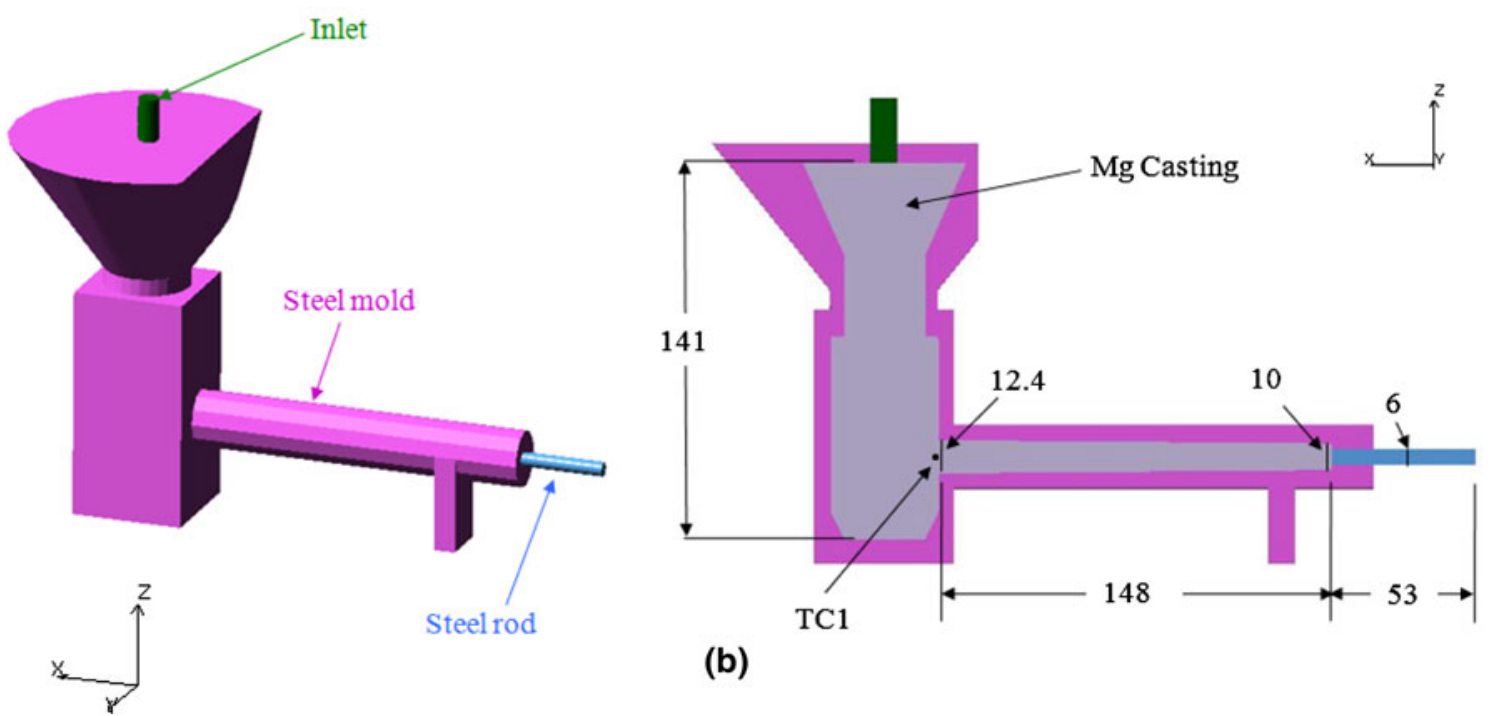

(b)

Fig. 1-Experimental test setup: (a) overall view and (b) geometry of the casting and the mold as used in the simulations (all dimensions in millimeters) 
circular rod is $12.4 \mathrm{~mm}$ at the sprue end and $10 \mathrm{~mm}$ at the opposite end. At the opposite end, a $53 \mathrm{~mm}$ long steel rod with a diameter of $6 \mathrm{~mm}$ is inserted into the casting. This steel rod extends out of the mold and is connected to a load sensor that measures the force that acts on the rod as the casting contracts. The mold, which is made of steel, and the load sensor are connected to a rigid steel platform. Thus, the thermal contraction of the rod section of the casting is constrained on one end by the sprue and on the other end by the rigid steel rod. As indicated in Figure 1(a) by the lines emanating from the mold, three thermocouples were used to monitor temperatures in the casting. All three temperature measurements were considered in tuning the thermal simulations described subsequently, but due to space limitations, only the temperatures measured with the thermocouple located at the junction between the sprue and the rod (labeled TC1 in Figure 1(b)) are reported here.

Experiments were conducted for two binary magnesium alloys containing 1 and 9 wt pet Al. The alloys did not contain any impurities. For each composition, castings were poured with three initial mold temperatures $\left(T_{\text {mold }}\right)$ of $523 \mathrm{~K}, 623 \mathrm{~K}$, and $773 \mathrm{~K}\left(250{ }^{\circ} \mathrm{C}\right.$, $350{ }^{\circ} \mathrm{C}$, and $500{ }^{\circ} \mathrm{C}$ ). For all six castings, the pouring superheat was $80 \mathrm{~K}\left(80^{\circ} \mathrm{C}\right)$ and the fill time was 5 seconds. The castings were allowed to cool in the mold until the temperature at the sprue-rod junction reached $573 \mathrm{~K}\left(300^{\circ} \mathrm{C}\right)$. In the experiments with the lower initial mold temperatures, extensive hot tears were found at the sprue-rod junction after the casting was removed from the mold. As shown in Reference 4 for a

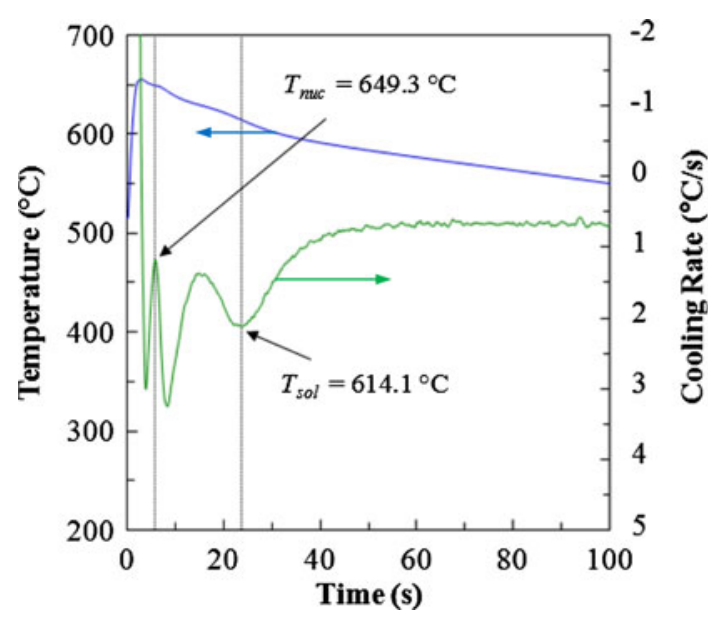

Fig. 2-Measured temperatures and cooling rates at the sprue-rod junction during the experiment with a $\mathrm{Mg}-1$ wt pet $\mathrm{Al}$ alloy and an initial mold temperature of $773 \mathrm{~K}\left(500^{\circ} \mathrm{C}\right)$. similar casting geometry, a lower initial mold temperature increases the hot tearing tendency because of the larger thermal contractions of the castings. No open hot tears were observed for the two castings with $T_{\text {mold }}=$ $773 \mathrm{~K}\left(500^{\circ} \mathrm{C}\right)$.

An example of temperatures measured at the spruerod junction during one of the experiments with the Mg-1 wt pet Al alloy is shown in Figure 2. The temperature $v s$ time data were converted to cooling rates, and the peaks in the cooling rate curves were used to obtain measured nucleation ( $\left.T_{\text {nuc }}\right)$ and final solidification $\left(T_{\text {sol }}\right)$ temperatures. As indicated in Figure 2, the nucleation (final solidification) temperature corresponds to a local minimum (maximum) in the cooling rate, since the rate of latent heat release is largest (smallest) at nucleation (the end of solidification). The values obtained for $T_{\text {nuc }}$ and $T_{\text {sol }}$ are listed for each of the six experiments in Table I. For the lower two initial mold temperatures, the cooling rates were too high to detect the nucleation peak. Table I shows that the final solidification temperature for the $\mathrm{Mg}-1 \mathrm{wt}$ pct $\mathrm{Al}$ alloy increases by $87 \mathrm{~K}$ $\left(87^{\circ} \mathrm{C}\right)$ for the initial mold temperature increasing from 523 to $773 \mathrm{~K}\left(250\right.$ to $\left.500{ }^{\circ} \mathrm{C}\right)$. This can be attributed to the cooling rate during solidification decreasing with increasing $T_{\text {mold }}$. A lower cooling rate allows for more back-diffusion of Al in the primary solid during solidification. Since no eutectic forms in the $\mathrm{Mg}-1$ wt pet Al alloy, increased back-diffusion causes the final solidification temperature to increase. For the $\mathrm{Mg}-9$ wt pet $\mathrm{Al}$ alloy, Table I shows a $15 \mathrm{~K}\left(15^{\circ} \mathrm{C}\right)$ range for the final solidification temperature. This range represents an estimate of the temperature at which the eutectic forms. Although one would expect for the Mg-9 wt pet Al alloy the eutectic to form isothermally, no pronounced temperature plateau was observed in the measured cooling curves (Figure 3(b)). Thus, only an approximate estimate of the eutectic temperature could be obtained from the temperature measurements.

\section{THERMAL SIMULATIONS}

A thermal simulation of each experiment, including the filling process, was performed using the software MAGMAsoft. ${ }^{[21]}$ The necessary thermophysical properties (thermal conductivity, viscosity, density, and apparent specific heat; all as a function of temperature) and solid fraction-temperature curves, $g_{s}(T)$, for each alloy were calculated using JMatPro. ${ }^{[22]}$ The liquidus temperatures predicted by JMatPro are equal to $918 \mathrm{~K}$ and $877 \mathrm{~K}\left(645^{\circ} \mathrm{C}\right.$ and $\left.604{ }^{\circ} \mathrm{C}\right)$ for the 1 and $9 \mathrm{wt}$ pet

Table I. Measured Nucleation and Final Solidification Temperatures

\begin{tabular}{llcllll}
\hline Temperature & \multicolumn{3}{c}{ Mg-1 Wt Pct Al } & Mg-9 Wt Pct Al \\
\hline$T_{\text {mold }}(\mathrm{K})$ & 523 & 623 & 773 & 523 & 623 & 350 \\
$T_{\text {mold }}\left({ }^{\circ} \mathrm{C}\right)$ & 250 & 350 & 500 & 250 & NA & NA \\
$T_{\text {nuc }}(\mathrm{K})$ & NA & NA & 922 & NA & NA & 693 \\
$T_{\text {nuc }}\left({ }^{\circ} \mathrm{C}\right)$ & NA & NA & 649 & 694 to 709 & 610 & 604 \\
$T_{\text {sol }}(\mathrm{K})$ & 800 & 832 & 887 & 421 to 436 & 422 to 437 \\
$T_{\text {sol }}\left({ }^{\circ} \mathrm{C}\right)$ & 527 & 559 & 614 & 698 to 713 \\
\hline
\end{tabular}




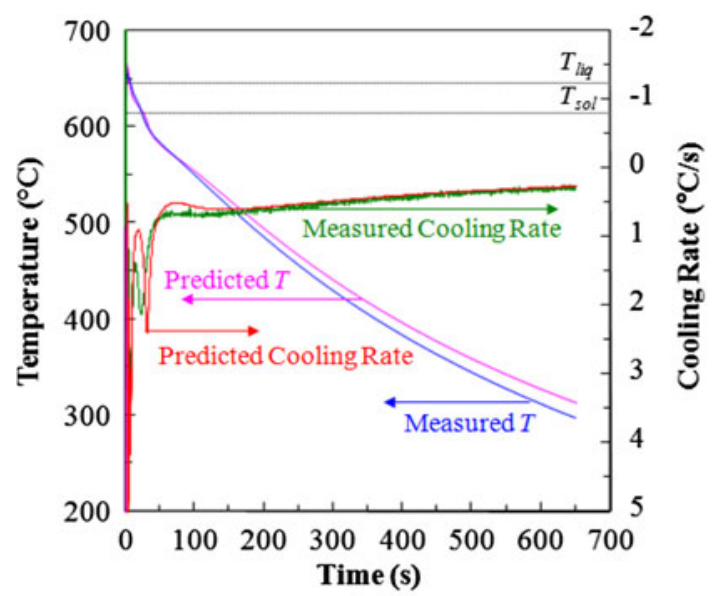

(a)

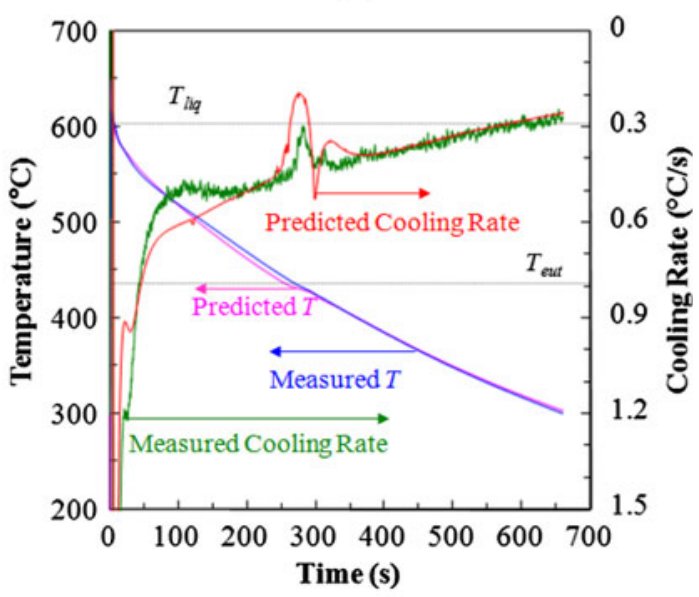

(b)

Fig. 3-Comparison of measured and predicted temperatures and cooling rates at the sprue-rod junction for an initial mold temperature of $773 \mathrm{~K}\left(500^{\circ} \mathrm{C}\right):(a) \mathrm{Mg}-1$ wt pet $\mathrm{Al}$ and $(b) \mathrm{Mg}-9$ wt pet $\mathrm{Al}$.

Al alloys, respectively. These values compare favorably with the measured nucleation temperatures $\left(T_{\text {nuc }}\right)$ listed in Table I. The solidification path was calculated using the Scheil model in JMatPro. For the Mg-9 wt pct Al alloy, the predicted eutectic temperature is $710 \mathrm{~K}$ $\left(437^{\circ} \mathrm{C}\right)$. This value is within the measured range of final solidification temperatures for this alloy in Table I. For the Mg-1 wt pet Al alloy, the strong variation in the measured final solidification temperature with cooling rate (Table I) was modeled by choosing different cut-off solid fractions in JMatPro. JMatPro readjusts the final portion of the $g_{s}(T)$ curve to smoothly approach a solid fraction of unity at the temperature of the cut-off. This allows for exact matching of measured and predicted final solidification temperatures. The cut-off solid fractions were found to be $1.16,1.68$, and 5.9 pct for the initial mold temperatures of $523 \mathrm{~K}, 623 \mathrm{~K}$, and $773 \mathrm{~K}$ $\left(250{ }^{\circ} \mathrm{C}, 350{ }^{\circ} \mathrm{C}\right.$, and $\left.500{ }^{\circ} \mathrm{C}\right)$, respectively. With these cut-off solid fractions, no eutectic is predicted to form. The preceding procedure is only approximate, but results in realistic $g_{s}(T)$ curves (and thermophysical properties) for each initial mold temperature. The final $g_{s}(T)$ curves for both alloys are plotted in Figures 11 and 12.
Another important input in the thermal simulations is the variation of the interfacial heat transfer coefficient (IHTC) between the mold and the metal as a function of temperature. The IHTC variation was determined in a trial-and-error process, where the IHTC was varied until good agreement between the measured and predicted temperatures at the sprue-rod junction was obtained. The IHTC variation that was found to give the best agreement can be described as follows: a constant value of 7000 $\mathrm{W} / \mathrm{m}^{2} \mathrm{~K}$ from the pouring temperature down to $T_{\text {sol }}$; below $T_{\text {sol }}$, a cubic decrease with temperature over a temperature interval of $50 \mathrm{~K}$ and $20 \mathrm{~K}\left(50{ }^{\circ} \mathrm{C}\right.$ and $\left.20{ }^{\circ} \mathrm{C}\right)$ for the 1 and $9 \mathrm{wt}$ pct $\mathrm{Al}$ alloy experiments, respectively, to a certain final value; and a constant final value of 200 and $400 \mathrm{~W} / \mathrm{m}^{2} \mathrm{~K}$ for the 1 and 9 wt pet Al alloy experiments, respectively, down to room temperature.

As shown in Figure 3 for two of the experiments, generally good agreement is obtained between the measured and predicted temperatures at the sprue-rod junction. Some of the discrepancies could have been reduced by further adjustments in the IHTC. However, much of the remaining disagreement can be attributed to the approximate nature of the $g_{s}(T)$ curves used in the simulations. This can be clearly seen in Figure 3(b) for the experiment with the Mg-9 wt pct Al alloy and $T_{\text {mold }}=773 \mathrm{~K}\left(500{ }^{\circ} \mathrm{C}\right)$. As opposed to the measured cooling curve, the predicted cooling curve shows a distinct plateau at the eutectic temperature (at about 275 seconds). This plateau corresponds to a strong minimum in the predicted cooling rate (also plotted in Figure 3(b)) and can be attributed to the release of latent heat during the formation of the eutectic. Although the measured cooling rate curve shows a qualitatively similar variation near the eutectic temperature (Figure 3(b)), the minimum is not nearly as pronounced as in the predictions. This disagreement indicates that in the experiment, less eutectic formed than what is predicted by the Scheil calculation within JMatPro. The predicted eutectic fraction is about 0.16 (Figure 12). In the experiments with the Mg-9 wt pet Al alloy, back-diffusion of $\mathrm{Al}$ in the primary solid during solidification results in the eutectic fraction to be less than that predicted in the Scheil limit (i.e., no back-diffusion). This effect is particularly strong for the experiment with $T_{\text {mold }}=773 \mathrm{~K}\left(500{ }^{\circ} \mathrm{C}\right)$, since the cooling rate is the lowest for this experiment. The overprediction of the eutectic fraction causes an underprediction of the primary solid fraction and, consequently, of the latent heat release at intermediate temperatures between the liquidus and eutectic. This can be clearly seen in Figure 3(b) by comparing the measured and predicted cooling rates between about 50 and 200 seconds. Despite these shortcomings in the $g_{s}(T)$ curves used in the present simulations, the overall agreement between the measured and predicted temperatures was still deemed acceptable. A back-diffusion model that would result in the calculation of a more accurate solidification path is not available within JMatPro. It was decided to nonetheless use JMatPro, since this software also provides the thermophysical properties needed in the thermal simulations. The uncertainties in $g_{s}(T)$ are estimated to be no larger than 10 pct. 


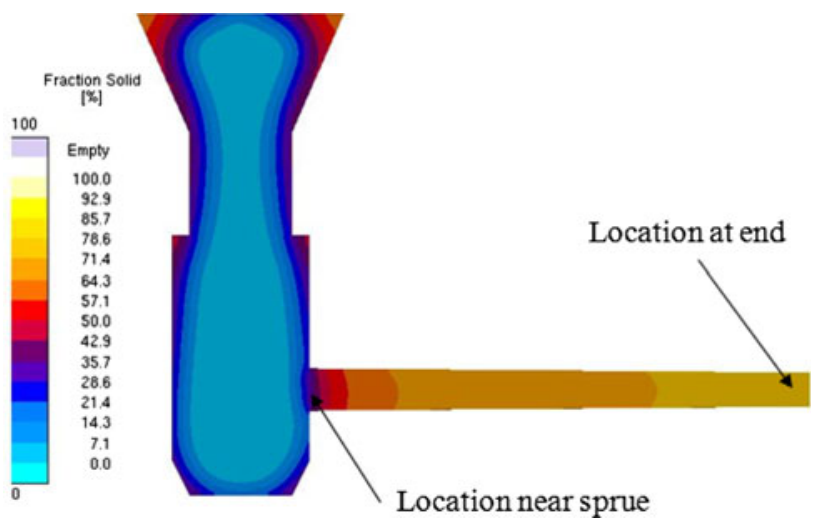

Fig. 4-Predicted solid fraction field at a time when the solid fraction at the sprue-rod junction reached a value of about 0.4 $\left(\mathrm{Mg}-9\right.$ wt pet $\left.\mathrm{Al}, T_{\text {mold }}=773 \mathrm{~K}\left(500^{\circ} \mathrm{C}\right)\right)$.

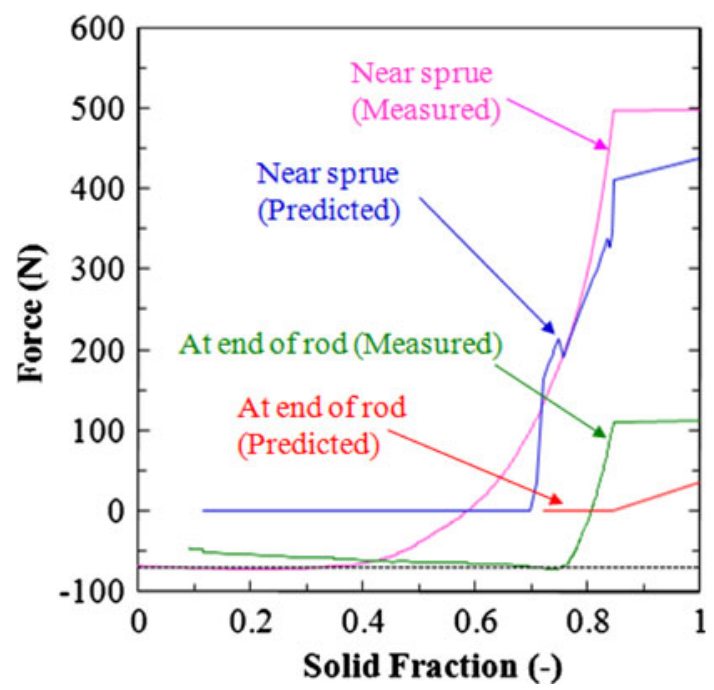

Fig. 5-Measured and predicted forces as a function of solid fraction at the two locations indicated in Fig. 4 (Mg-9 wt pct $\mathrm{Al}$, $\left.T_{\text {mold }}=773 \mathrm{~K}\left(500^{\circ} \mathrm{C}\right)\right)$.

Figure 4 shows an example of a predicted solid fraction field at an intermediate time during solidification $\left(\mathrm{Mg}-9\right.$ wt pct $\mathrm{Al}, T_{\text {mold }}=773 \mathrm{~K}\left(500{ }^{\circ} \mathrm{C}\right)$ ). The lowest solid fraction occurs in the lower center portion of the sprue, which represents a hot spot. In the horizontal rod section, the solid fraction increases with increasing distance from the sprue. Hence, the solid fraction is always lower at the sprue-rod junction than at the end of the rod where the steel rod is inserted. Also note that there exists a relatively strong solid fraction gradient at the sprue-rod junction.

With the knowledge of the evolution of the solid fraction field, the measured contraction force can now be plotted as a function of the solid fraction at any chosen location in the casting. As an example, Figure 5 shows the force measured in the Mg-9 wt pct $\mathrm{Al}$, $T_{\text {mold }}=773 \mathrm{~K}\left(500^{\circ} \mathrm{C}\right)$ experiment plotted against two different solid fractions: at the sprue-rod junction and at the end of the rod section (Figure 4). Hence, there are two measured force curves in Figure 5, even though only one force is measured. It can be seen that considerable tensile forces build up in the rod section when the alloy is still in a semisolid state. In fact, the force starts to increase from zero (ignoring the negative offset from the load cell) when the solid fraction at the sprue-rod junction is approximately 0.45 (pink line). At the same time (or force), the solid fraction at the end of the rod section, where the steel rod is inserted, is about 0.75 (green line). This indicates that the onset of coherency of the mush is between 40 and 50 pct solid. These values are much lower than the 0.87 zero-strength solid fraction measured in the reheating experiments of $\mathrm{Hu}$ et al. ${ }^{[11]}$ for an AZ31 magnesium alloy. Figure 5 shows that for solid fractions above coherency, the measured force, and hence the strength of the mush, increases rapidly. These variations are further examined subsequently when the measurements are compared to the predictions of the stress model.

\section{STRESS MODEL}

The present stress simulations were performed using the model by Monroe and co-workers. ${ }^{[3-5]}$ Only a brief summary of this model is provided here. It uses a somewhat simplified version of the viscoplastic constitutive model for mush by Ludwig et al., ${ }^{[6]}$ in that it does not consider a separate internal variable for the cohesion state of the solid. Neglecting forces due to gravity and interactions with the liquid, the effective stress tensor for porous solids, $\boldsymbol{\sigma}$, is governed by

$$
\nabla \cdot \boldsymbol{\sigma}=0
$$

The total strain is given by the sum of the thermal, elastic, and viscoplastic strains as $\varepsilon=\varepsilon^{t h}+\varepsilon^{e}+\varepsilon^{v p}$.

The thermal strain is calculated using the density of the solid as a function of temperature provided by JMatPro. The measured forces shown in Figure 5 indicate that thermal contractions take place even when the alloy is still in a semisolid state. Therefore, the thermal strain is integrated starting at a temperature that corresponds to a certain solid fraction, $g_{s}^{\text {th }}$, below unity. Based on the work of Stangeland et al. ${ }^{[8]}$ $g_{s}^{\text {th }}$ was estimated to be equal to 0.94 and 0.84 for the 1 and 9 wt pet Al alloys, respectively. By choosing $g_{s}^{\text {th }}=0.84$ for the $\mathrm{Mg}-9$ wt pct $\mathrm{Al}$ alloy, the relatively large density change associated with the formation of the eutectic is taken into account in the thermal strain calculations.

The elastic strain is determined using Hooke's law. The elastic stiffness tensor is defined in terms of the Young's modulus, E, and the Poisson ratio, v. For temperatures above $T_{\text {sol }}$, these elastic constants are reduced due to the presence of liquid according to ${ }^{[23]}$

$$
\begin{gathered}
E=E_{s}\left(\frac{g_{s}-g_{s}^{\mathrm{coh}}}{1-g_{s}^{\mathrm{coh}}}\right)^{2.5} \\
v=0.14+\left(\frac{g_{s}-g_{s}^{\mathrm{coh}}}{1-g_{s}^{\mathrm{coh}}}\right)\left(v_{s}-0.14\right)
\end{gathered}
$$


where $g_{s}^{\text {coh }}$ is the coherency solid fraction, and $E_{s}$ and $v_{s}$ are the Young's modulus and Poisson ratio, respectively, of the solid only. According to the discussion of Figure 5, the coherency solid fraction is taken to be $g_{s}^{\mathrm{coh}}=0.5$.

The viscoplastic strain rate is obtained from an associative flow law,

$$
\dot{\varepsilon}^{v p}=\dot{\gamma} \frac{\partial f_{Y}}{\partial \boldsymbol{\sigma}}
$$

where $\dot{\gamma}$ is a scalar flow parameter. This flow parameter is zero during elastic deformation but must be calculated when inelastic deformation occurs. The value of the flow parameter is found by using the yield function, which during inelastic flow must be equal to zero. In the present study, the quadratic yield function, $f_{Y}$, for porous material plasticity of Cocks ${ }^{[24]}$ is adopted

$$
f_{Y}=q^{2}+A_{1} p^{2}-A_{2} \sigma_{d y}^{2} \leq 0
$$

in which the solid pressure and the von Mises stress are given by $p=-(\boldsymbol{\sigma}: \boldsymbol{I}) / 3$ and $q=2|\boldsymbol{\sigma}+p \boldsymbol{I}| / 3$, respectively. The functions $A_{1}$ and $A_{2}$ are given, respectively, by

$$
\begin{gathered}
A_{1}=\frac{9\left(1-g_{s}^{*}\right)}{2\left(2-g_{s}^{*}\right)(1+m)\left[1+2\left(1-g_{s}^{*}\right) / 3\right]} \\
A_{2}=\left[1+2\left(1-g_{s}^{*}\right) / 3\right]^{-1}\left(g_{s}^{*}\right)^{2 /(1+m)}
\end{gathered}
$$

where $m$ is the strain-rate-sensitivity coefficient. The scaled solid fraction is given by $g_{s}^{*}=g_{s}^{\text {coal }}\left(g_{s}-g_{s}^{\text {coh }}\right) /$ $\left(g_{s}^{\text {coal }}-g_{s}^{\text {coh }}\right)$, where $g_{s}^{\text {coal }}$ is the solid fraction below which voids (not the solid) coalesce and the mush rapidly weakens. As a first approximation, a value of 0.85 was chosen for the coalescence solid fraction. This value is also approximately equal to the solid fraction at which the eutectic forms for the $\mathrm{Mg}-9$ wt pct $\mathrm{Al}$ alloy. Note that when $g_{s}^{*}=1$, the preceding model reduces to a classical von Mises yield model.

The dynamic yield stress in Eq. [5] includes both hardening and creep effects and is calculated from

$$
\sigma_{d y}=\sigma_{0}\left(1+\varepsilon_{e q} / \varepsilon_{0}\right)^{n}\left(1+\dot{\varepsilon}_{e q} / \dot{\varepsilon}_{0}\right)^{m}
$$

where $\sigma_{0}$ is the initial yield stress, $\varepsilon_{0}=\sigma_{0} n / E$ is a reference strain, $n$ is the strain hardening coefficient, and $\dot{\varepsilon}_{0}$ is a temperature-dependent reference strain rate. Due to a lack of data, $\dot{\varepsilon}_{0}$ is taken as a constant equal to $10^{-5} 1 / \mathrm{s}$. The equivalent strain rate is found from the scalar dissipation of energy according to $\dot{\varepsilon}_{e q}=\boldsymbol{\sigma}: \underline{\varepsilon}^{v p} /\left(g_{s} \sigma_{d y}\right)$. The equivalent strain, $\varepsilon_{e q}$, is obtained by integrating the equivalent strain rate over time for temperatures below the annealing temperature. The annealing temperature is taken to be equal to $T_{\text {sol }}$.

A damage volume fraction is calculated by integrating the volumetric part of the viscoplastic strain rate over time according to

$$
g_{d}=\int_{t_{d}}^{t} g_{s} \dot{\varepsilon}^{p p}: \mathbf{I} d t
$$

where $t_{d}$ is the time when the damage is initiated. In order to calculate the entire accumulated damage, $t_{d}$ is taken as the time when $g_{s}$ reaches $g_{s}^{\text {coh }}=0.5$. The effect of the damage on the mechanical behavior of the mush is taken into account by reducing $g_{s}$ by $g_{d}$ in the present constitutive equations. The damage volume fraction, as defined previously, should not be taken as a predictor for hot tears. In order to predict open hot tears, only the damage that is accumulated after the feeding flow is cut off should be used. ${ }^{[5]}$ Typically, the feeding flow is not cut off until the solid fraction is well above 0.9. If the feeding flow is not cut off, the semisolid mush can still be damaged and weakened by a tensile viscoplastic strain, but liquid will flow into the damaged area to compensate for the volume change. Feeding flow calculations are not performed in the present study.

The preceding stress model was implemented in a special module of MAGMAsoft. ${ }^{[21]}$ The steel mold and rod were assumed to be rigid and the contact between the casting and the mold was appropriately accounted for. The thermal and stress simulations were performed sequentially. In other words, the thermal results were used in the stress simulations, but the stress results were not used in the thermal simulations.

\section{MECHANICAL PROPERTIES}

Except for the initial yield stress at temperatures above $573 \mathrm{~K}\left(300{ }^{\circ} \mathrm{C}\right)$, the mechanical properties needed in the stress model were estimated from data available in the literature. Due to a lack of suitable data, many of these estimates should only be considered as first approximations.

Figure 6 shows the variation of Young's modulus with temperature that was used for the Mg-9 wt pet Al alloy. The data in Figure 6 from Busk ${ }^{[13]}$ are for an AZ91 alloy, which contains 9 wt pet Al. They were extrapolated linearly to higher temperatures; i.e., the

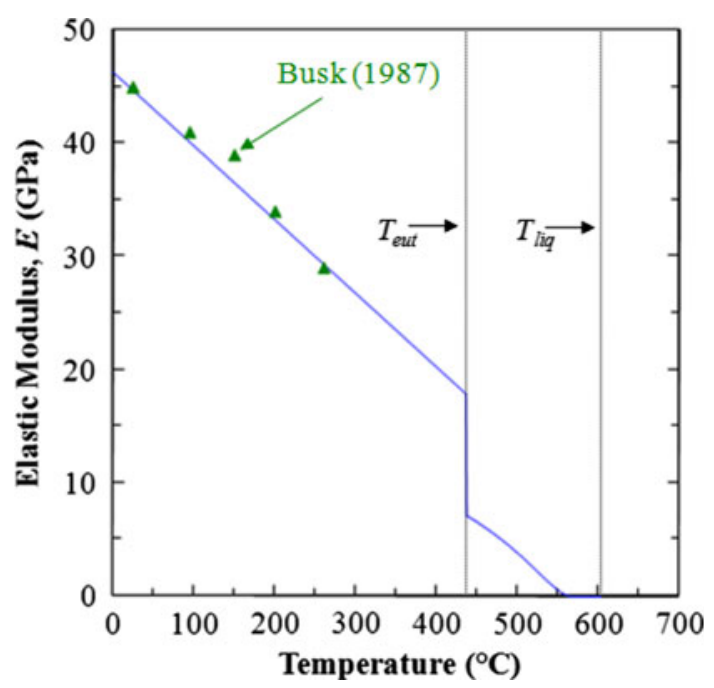

Fig. 6-Young's modulus variation with temperature for the Mg-9 wt pet Al alloy. 
elastic modulus of the solid, $E_{s}$, was assumed to vary linearly from room temperature to $T_{\text {liq }}$. The nonlinear variation in the effective modulus, $E$, above $T_{\text {sol }}=T_{\text {eut }}$ that can be seen in Figure 6 reflects the effect of the solid fraction, as modeled by Eq. [2]. In particular, the abrupt change in $E$ at $T_{\text {eut }}$ is due to the fact that the eutectic forms isothermally. Also note that $E$ vanishes at a temperature corresponding to $g_{s}^{\text {coh }}=0.5$, rather than at $T_{\text {liq. }}$. The same $E_{s}$ data were used for both the 1 and 9 wt pet Al alloys. Young's modulus is not expected to be a strong function of composition.

The Poisson ratio of the solid, $v_{s}$, was taken as a constant equal to $0.35,{ }^{[14]}$ as no temperature- or composition-dependent data were found in the literature.

The strain-rate-sensitivity coefficient, $m$, variation with temperature was estimated by fitting a straight line to values obtained from the literature, ${ }^{[12,13,16,18,19]}$ as shown in Figure 7. The same variation was used for both binary alloys of the present study, even though the data points are all for AZ91. Some of the data were determined from stress-strain curves at various temperatures and strain rates, ${ }^{[12,13,16]}$ while others are directly reported values. ${ }^{[18,19]}$

Room-temperature values for the strain hardening coefficient, $n$, were determined by fitting the as-cast binary $\mathrm{Mg}$-Al alloy stress-strain curves of $\mathrm{Cao}$ and Wessen $^{[17]}$ to Eq. [8] (with $m=0$ ). The resulting variation of the room temperature $n$ with $\mathrm{Al}$ content is shown in Figure 8(a). The temperature dependence of the strain hardening coefficient was estimated by assuming that $n$ varies linearly with temperature, from the room-temperature value for a given $\mathrm{Al}$ content in Figure 8(a) to zero at $T_{\text {sol }}$. The resulting variation of $n$ for the Mg-9 wt pet Al alloy is shown in Figure 8(b).

Room-temperature values for the initial yield stress, $\sigma_{0}$, were also determined from the fits of the binary Mg-Al alloy stress-strain curves of Cao and Wessen ${ }^{[17]}$ to Eq. [8] (with $m=0$ ). Figure 9(a) shows that $\sigma_{0}$ is a strong function of the Al content. The room-temperature

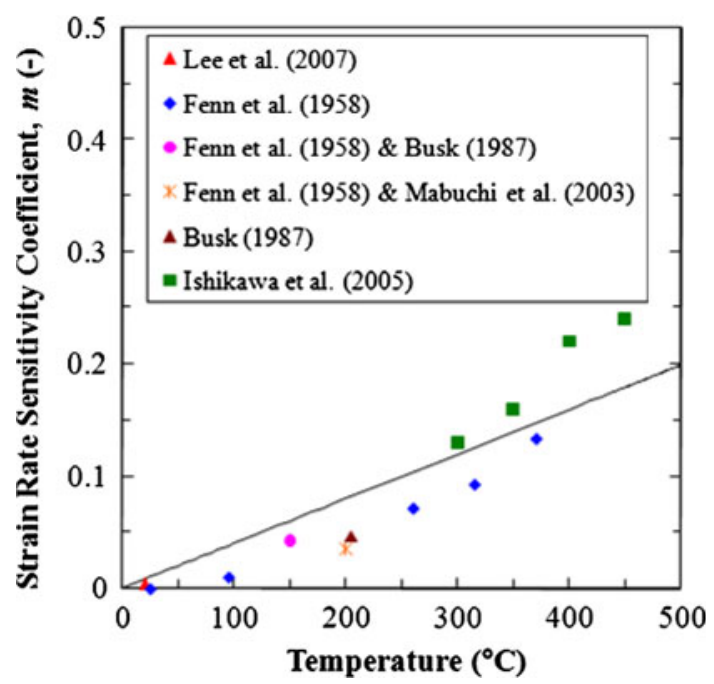

Fig. 7-Strain-rate-sensitivity coefficient variation with temperature; the data are for AZ91. initial yield stress for the $\mathrm{Mg}-1$ wt pet $\mathrm{Al}$ alloy is about $8 \mathrm{MPa}$, while it is $74 \mathrm{MPa}$ for the $\mathrm{Mg}-9$ wt pet Al alloy. The calculated variation of the room temperature 0.2 pct offset yield stress with $\mathrm{Al}$ content is shown in Figure 9(b). It is encouraging to see that several values reported in the literature for the room temperature 0.2 pct offset yield stress of as-cast AZ91 ${ }^{[13,15,20]}$ fall well within the variation obtained from the fits of the binary Mg-Al stress-strain curves of Cao and Wessen. ${ }^{[17]}$ The room-temperature values for the 0.2 pct offset yield stress of the $\mathrm{Mg}-1$ and $9 \mathrm{wt}$ pct $\mathrm{Al}$ alloys are about 35 and $83 \mathrm{MPa}$, respectively.

The temperature dependence of $\sigma_{0}$ was estimated by assuming that it decreases linearly with temperature, starting from the room-temperature value for a given Al content in Figure 9(a), down to a certain Al content dependent value at $573 \mathrm{~K}\left(300^{\circ} \mathrm{C}\right)$. The values for $\sigma_{0}$ at $573 \mathrm{~K}\left(300^{\circ} \mathrm{C}\right)$, as well as the temperature variations of $\sigma_{0}$ above $573 \mathrm{~K}\left(300{ }^{\circ} \mathrm{C}\right)$, were obtained by comparing

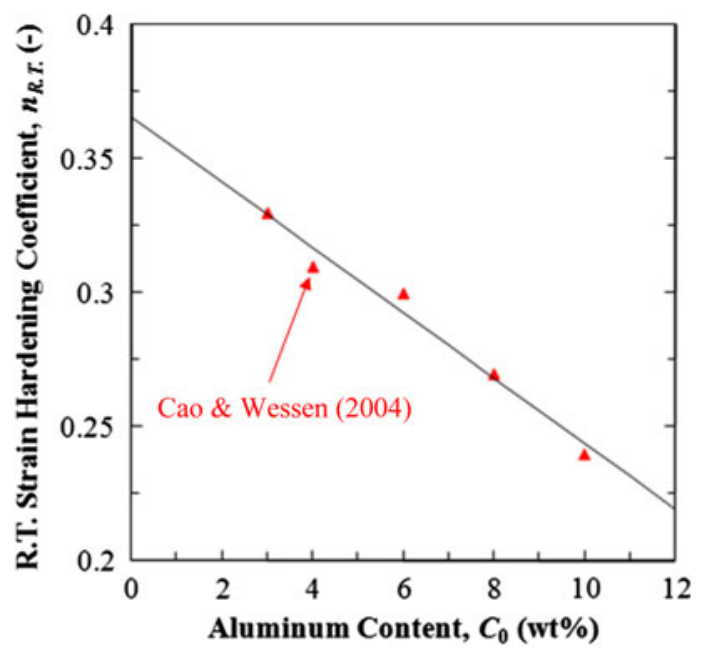

(a)

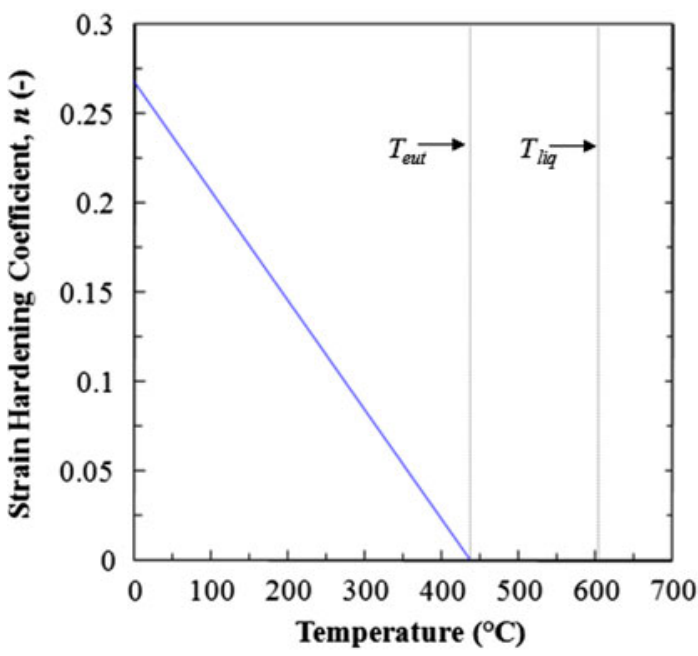

(b)

Fig. 8- Strain hardening coefficient: (a) room-temperature variation with aluminum content obtained from the binary $\mathrm{Mg}$-Al alloy stressstrain curves of Cao and Wessen, ${ }^{[17]}$ and $(b)$ estimated variation with temperature for the $\mathrm{Mg}-9 \mathrm{wt}$ pct $\mathrm{Al}$ alloy. 


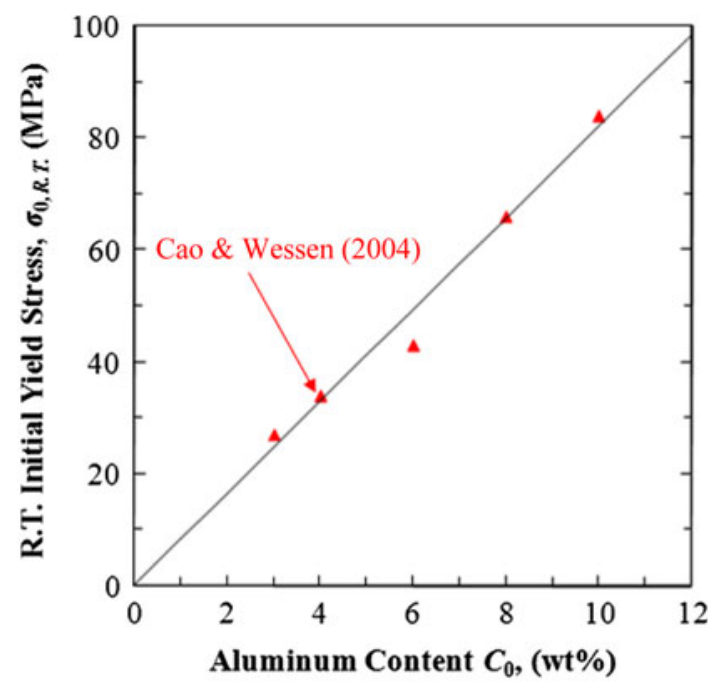

(a)

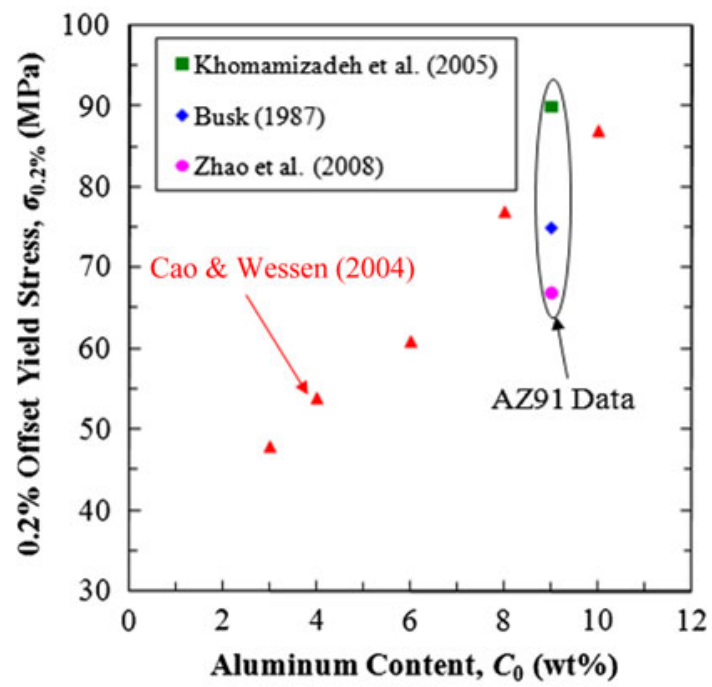

(b)

Fig. 9-Room-temperature yield stress variation with aluminum content obtained from the binary $\mathrm{Mg}-\mathrm{Al}$ alloy stress-strain curves of Cao and Wessen: $:^{[17]}(a)$ initial yield stress and $(b) 0.2$ pct offset yield stress together with several values for AZ91.

measured and predicted forces in the present experiments, as explained in detail in Section VI. Recall that the experiments were terminated when the temperature at the sprue-rod junction reached $573 \mathrm{~K}\left(300^{\circ} \mathrm{C}\right)$. Hence, the assumed mechanical property variations below $573 \mathrm{~K}\left(300{ }^{\circ} \mathrm{C}\right)$ have little effect on the predicted stress results.

\section{RESULTS}

Predicted stress, strain, and distortion results for one of the experiments $\left(\mathrm{Mg}-9 \mathrm{wt}\right.$ pct $\mathrm{Al}, T_{\text {mold }}=773 \mathrm{~K}$ $\left(500{ }^{\circ} \mathrm{C}\right)$ ) are shown in Figure 10 . These results are at a time when the sprue-rod junction reached a temperature of $573 \mathrm{~K}\left(300{ }^{\circ} \mathrm{C}\right)$. The stresses are mostly confined to the rod section of the casting, where they are positive (tensile), relatively uniform, and in a direction along the

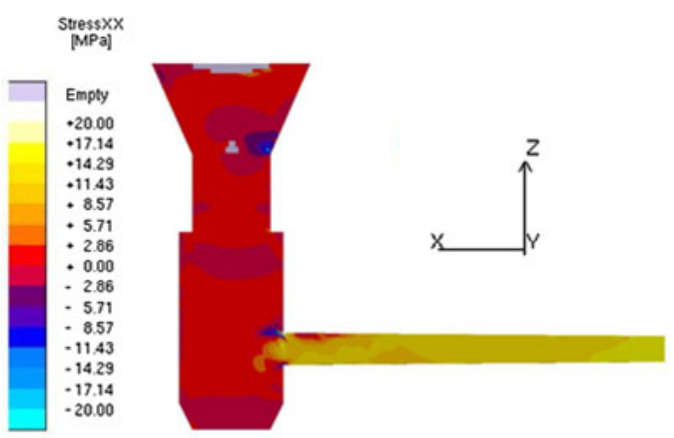

(a)

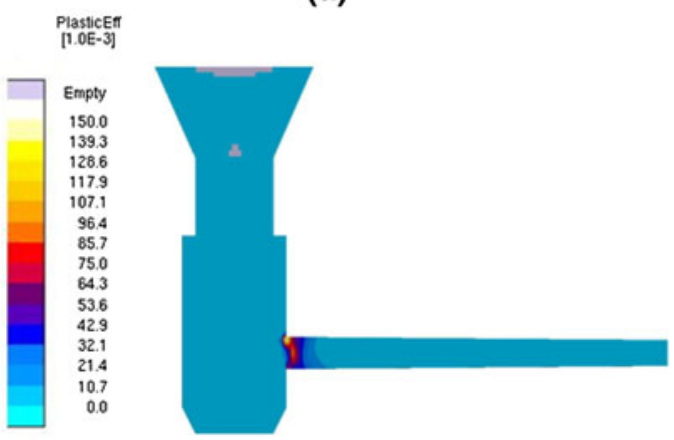

(b)
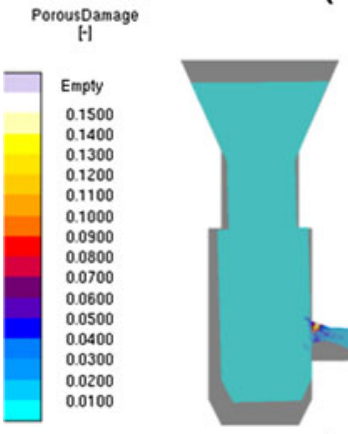

(c)

Fig. 10 - Predicted stress, strain, and distortion results at the end of the $\mathrm{Mg}-9$ wt pet $\mathrm{Al}, T_{\text {mold }}=773 \mathrm{~K}\left(500^{\circ} \mathrm{C}\right)$ experiment: $(a) x$-direction stress, $(b)$ plastic effective strain, and $(c)$ distortion (20 times magnified) and damage.

rod axis. Compressive stresses, due to contact with the mold, are present near the sprue-rod junction and in the upper part of the sprue. The plastic effective strain, as well as the damage porosity, is entirely confined to the sprue-rod junction, which represents the weakest point in the rod. Figure 10(c) reveals a complex distortion pattern, with multiple areas where the casting contacts the mold.

Figure 11, for the Mg-1 wt pet Al alloy, and Figure 12, for the Mg-9 wt pet Al alloy, show a comparison of measured and predicted stresses at the sprue-rod junction for each of the three initial mold temperatures. In order to view the experimental force measurements in terms of stress, the forces were divided by the crosssectional area of the rod section of the casting at the sprue-rod junction. The measured and predicted stresses in Figures 11 and 12 are plotted, respectively, against 


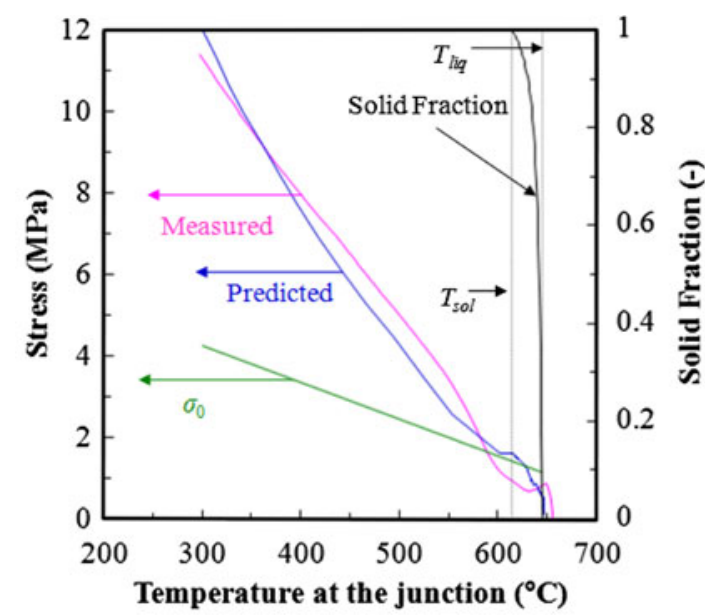

(a)

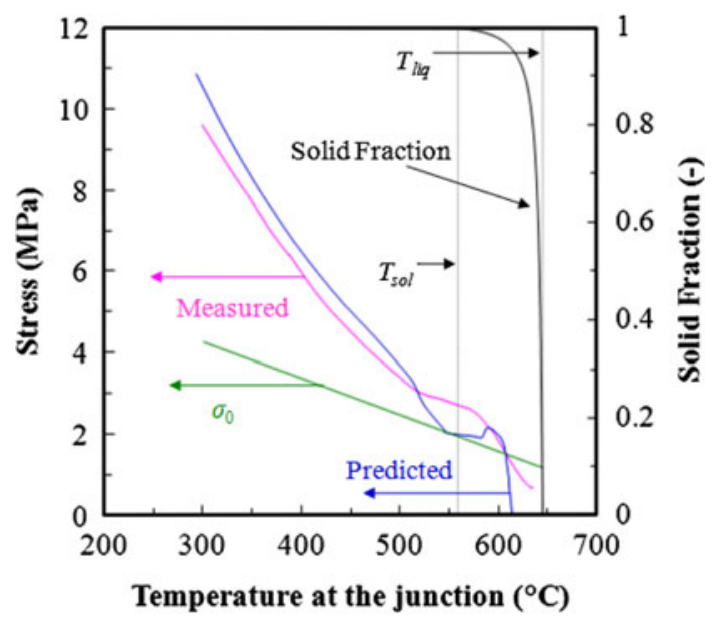

(b)

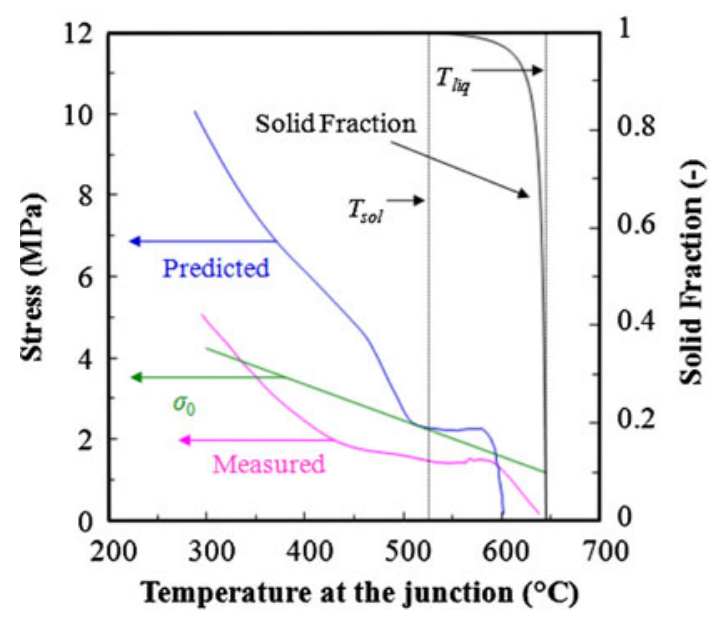

(c)

Fig. 11-Comparison of measured and predicted stresses at the sprue-rod junction for the Mg-1 wt pet $\mathrm{Al}$ castings, together with the initial yield stress- and solid fraction-temperature curves used in the simulations: (a) $T_{\text {mold }}=773 \mathrm{~K} \quad\left(500{ }^{\circ} \mathrm{C}\right), \quad(b) \quad T_{\text {mold }}=623 \mathrm{~K}$ $\left(350^{\circ} \mathrm{C}\right)$, and $(c) T_{\text {mold }}=523 \mathrm{~K}\left(250^{\circ} \mathrm{C}\right)$.

the measured and predicted temperatures at the spruerod junction. Superimposed in these graphs are the solid fraction-temperature curves for the six experiments.

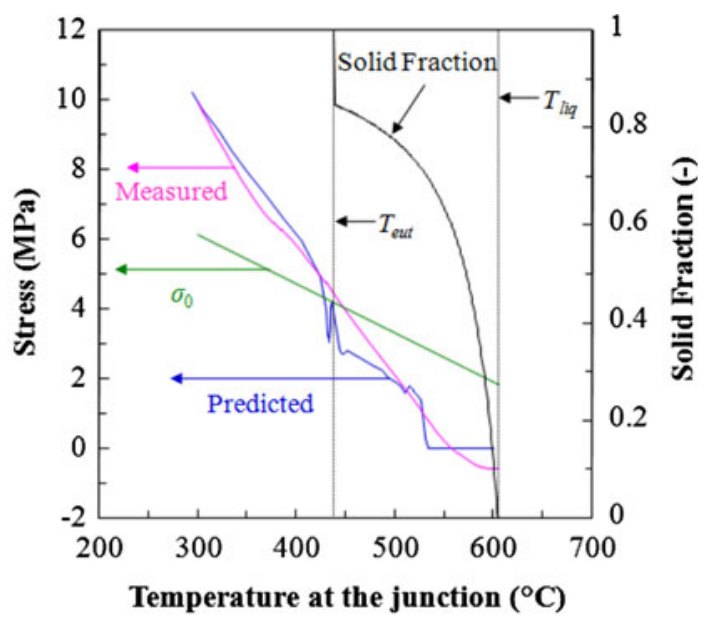

(a)

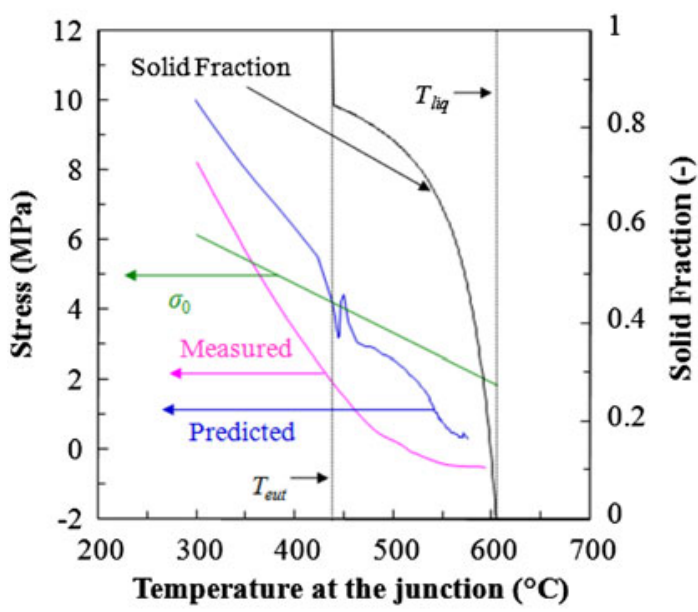

(b)

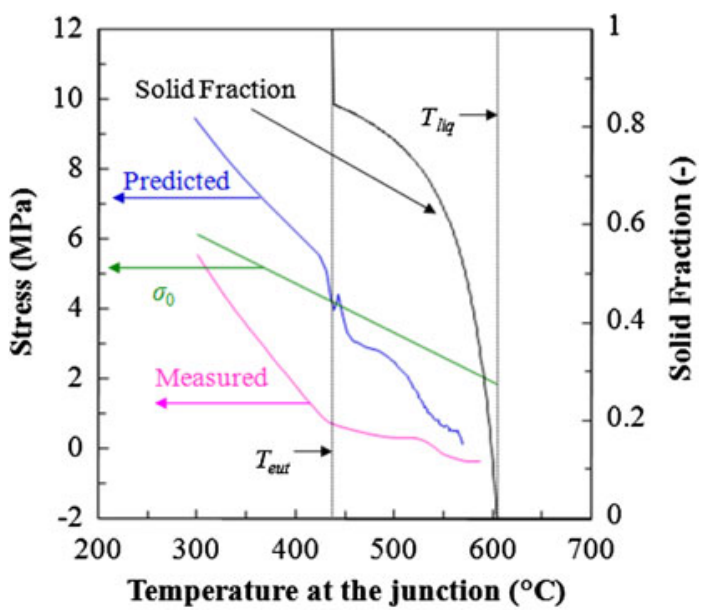

(c)

Fig. 12-Comparison of measured and predicted stresses at the sprue-rod junction for the Mg-9 wt pct Al castings, together with the initial yield stress- and solid fraction-temperature curves used in the simulations: (a) $T_{\text {mold }}=773 \mathrm{~K} \quad\left(500^{\circ} \mathrm{C}\right), \quad(b) \quad T_{\text {mold }}=623 \mathrm{~K}$ $\left(350{ }^{\circ} \mathrm{C}\right)$, and $(c) T_{\mathrm{mold}}=523 \mathrm{~K}\left(250{ }^{\circ} \mathrm{C}\right)$.

Since the two experiments with an initial mold temperature of $773 \mathrm{~K}\left(500^{\circ} \mathrm{C}\right)$ (Figures 11(a) and 12(a)) did not have visible hot tears, they were used to 
estimate the initial yield stress, $\sigma_{0}$, variation with temperature for the $\mathrm{Mg}-1$ and $9 \mathrm{wt}$ pct $\mathrm{Al}$ alloys at temperatures above $573 \mathrm{~K}\left(300{ }^{\circ} \mathrm{C}\right)$. This was done in an iterative fashion, by matching the measured and predicted stresses at the sprue-rod junction between $573 \mathrm{~K}$ $\left(300{ }^{\circ} \mathrm{C}\right)$ and the final solidification temperature, $T_{\text {sol }}$ (which is equal to the eutectic temperature, $T_{\text {eut }}$, for the Mg-9 wt pet Al alloy). First, a linear variation of $\sigma_{0}$ with temperature was assumed between $573 \mathrm{~K}\left(300{ }^{\circ} \mathrm{C}\right)$ and the liquidus temperature, $T_{\text {liq. }}$. Then, multiple stress simulations were performed with different $\sigma_{0}$ variations, until a good match of the measured and predicted stresses between $573 \mathrm{~K}\left(300^{\circ} \mathrm{C}\right)$ and $T_{\text {sol }}$ was achieved. The resulting $\sigma_{0}$ vs temperature curves are included in Figures 11 and 12 and plotted separately in Figure 13. Figure 13 shows that the $\sigma_{0}$ curves are not the same for the $\mathrm{Mg}-1$ and $9 \mathrm{wt}$ pet $\mathrm{Al}$ alloys. At a temperature of $573 \mathrm{~K}\left(300^{\circ} \mathrm{C}\right), \sigma_{0} \approx 4.2$ and $6 \mathrm{MPa}$ for the $\mathrm{Mg}-1$ and 9 wt pet Al alloys, respectively. At the final solidification temperature, $T_{\text {sol }}$, which is very different for the two alloys, $\sigma_{0} \approx 1.5$ and $4 \mathrm{MPa}$ for the Mg-1 and 9 wt pet Al alloys, respectively. As can be seen from Figures 11(a) and $12(\mathrm{a})$, at $T_{\text {sol }}$, the initial yield stress is approximately equal to the predicted total tensile stress. Recall that $\mathrm{Hu}$ et al. ${ }^{[11]}$ reported a maximum tensile stress at $T_{\text {sol }}$ of $13 \mathrm{MPa}$ for an AZ31 alloy (with $3 \mathrm{wt}$ pet $\mathrm{Al}$ and 1 wt pet $\mathrm{Zn}$ ). This value is much above the present range of 1.5 to $4 \mathrm{MPa}$ for the $\mathrm{Al}$ content varying from 1 to 9 wt pet. The disagreement is likely due to the fact that the measurements of $\mathrm{Hu}$ et al. ${ }^{[11]}$ are based on reheating experiments, while the present measurements are performed in situ during solidification.

Returning to Figures 11(a) and 12(a), it can be seen that for the two experiments with the initial mold temperature of $773 \mathrm{~K}\left(500{ }^{\circ} \mathrm{C}\right)$, the agreement between the measured and predicted stresses is good over the entire temperature range of the experiments. For temperatures between $573 \mathrm{~K}\left(300{ }^{\circ} \mathrm{C}\right)$ and $T_{\text {sol }}$, the agreement is not surprising since the initial yield stress was adjusted until the measured and predicted stresses agreed. Note that below $T_{\text {sol }}$, the predicted stresses are above the initial yield stress, $\sigma_{0}$, which is due to hardening and creep effects (Eq. [8]). More importantly, the agreement between the measured and predicted stresses remains reasonably good throughout the solidification range (i.e., above $T_{\text {sol }}$ ). This can be seen particularly well in Figure 12(a) for the $\mathrm{Mg}-9$ wt pct Al alloy, since for this alloy, the solidification temperature range is very wide (for the $\mathrm{Mg}-1 \mathrm{wt}$ pct $\mathrm{Al}$ alloy in Figure 11(a), the solidification range is too small to make any definite conclusions). Above $T_{\text {sol }}$ (which is equal to the eutectic temperature for the Mg-9 wt pct Al alloy), the predicted stress is below the initial yield stress, $\sigma_{0}$, because the presence of liquid weakens the mush (Eq. [5]). The predicted stress changes rapidly with temperature during the formation of the eutectic, which is expected since the eutectic forms isothermally. The measured stress, on the other hand, shows a smoother variation around the eutectic temperature. This discrepancy can be attributed to the overprediction of the eutectic fraction for the $\mathrm{Mg}-9$ wt pet Al alloy (with $\left.T_{\text {mold }}=773 \mathrm{~K}\left(500^{\circ} \mathrm{C}\right)\right)$, as discussed in Section III.
With increasing temperature, the predicted stress continues to decrease, until it vanishes when the solid fraction at the sprue-rod junction reaches a value of about 0.7. This can be seen more clearly in Figure 5, where the measured and predicted forces for the experiment corresponding to Figure 12(a) are plotted directly as a function of the solid fraction. Figure 5 shows that the predicted force starts to increase from zero when the solid fraction at the end of the rod reaches the solid fraction for the onset of thermal contractions, $g_{s}^{t h}$, which is equal to 0.84 for the Mg-9 wt pet Al alloy. In the absence of thermal contractions (i.e., for solid fractions everywhere in the rod section below $g_{s}^{\text {th }}$ ), the predicted forces are equal to zero. At the time the solid fraction at the end of the rod reaches $g_{s}^{\text {th }}$ and the predicted force starts to increase, the solid fraction at the sprue-rod junction is equal to 0.7 , which is well above the assumed coherency solid fraction, $g_{s}^{\text {coh }}=0.5$. Hence, in the simulation, the start of the force increase is controlled by the onset of thermal contractions at the end of the rod. In comparison, the measured force starts to increase from zero when the solid fraction at the end of the rod is equal to about 0.75 , at which time the solid fraction at the sprue-rod junction is equal to about 0.45 , as noted in Section III. This indicates that the model could be improved by choosing a somewhat lower value for $g_{s}^{\text {th }}$ for the Mg-9 wt pet Al alloy (e.g., 0.75 instead of $0.84)$. However, it is possible that thermal contractions occur for solid fractions below 0.75 , because the force cannot build up until the solid fraction at the sprue-rod junction reaches the coherency solid fraction. In the experiment, the start of the force increase is controlled by reaching coherency at the sprue-rod junction, rather than by the onset of thermal contractions at the end of the rod, as in the simulation. Clearly, additional experiments are needed to clarify this aspect of the stress model. It should be kept in mind that the agreement between the measured and predicted stresses is affected by numerous other modeling aspects, including the variation of the initial yield stress of the solid above $T_{\text {sol }}$ (which was linearly extrapolated to $T_{\text {liq }}$; Figure 13), the yield function used for the semisolid mush, the solid fraction-temperature relation, the predicted temperatures, and perhaps even thermal contractions of the mold. In view of these uncertainties, the agreement for the experiments without hot tears can be deemed to be quite reasonable.

As shown in Figures 11(c), 12(b), and 12(c), the agreement between the measured and predicted stresses does not remain good for the experiments with the lower initial mold temperatures where significant hot tears were observed. Recall that lower initial mold temperatures cause larger thermal contractions. For those experiments, the measured stresses are significantly below the predicted ones. The discrepancies originate during solidification. Starting at solid fractions between 0.4 and 0.5 , the semisolid mush develops some coherency and strength. At higher solid fractions (or lower temperatures), however, the measured stresses remain about constant or increase only slightly, whereas they increase substantially in the experiments without hot tears. This indicates that in the presence of a large tensile strain during solidification, 


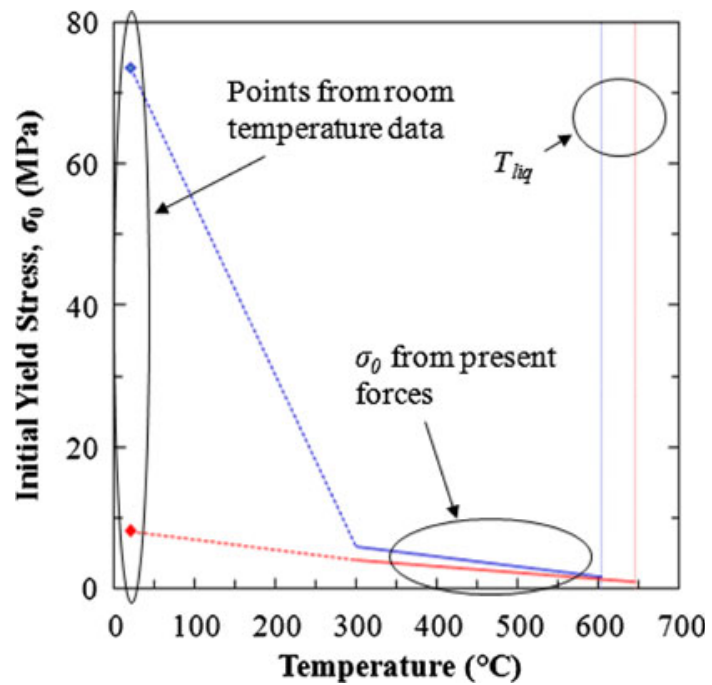

Fig. 13-Initial yield stress variation with temperature for the Mg-1 wt pet Al (red lines) and Mg-9 wt pet Al (blue lines) alloys. The dashed lines, which are of a purely hypothetical nature, connect the $\sigma_{0}$ values at $573 \mathrm{~K}\left(300{ }^{\circ} \mathrm{C}\right)$ determined in the present study to the room-temperature values obtained from the binary $\mathrm{Mg}-\mathrm{Al}$ alloy stress-strain curves of Cao and Wessen ${ }^{[17]}$ (Fig. 9(a)).

the increase in coherency and strength of the mush with decreasing temperature and increasing solid fraction can be completely negated by fracture of the mush. The fracture of the mush at the sprue-rod junction is not complete; i.e., the stress does not vanish completely. This can be attributed to the fact that only a portion of the sprue-rod junction is fractured or that new solid bridges between dendrite arms are formed continually during solidification. Even though the present model takes into account the effect of the damage volume on the yielding behavior of the mush, and considerable damage is predicted (Figure 10(c)), the predicted stresses are not reduced sufficiently to match the measured stresses in the experiments with hot tears. Clearly, a model of the actual fracture process must be implemented in order to improve the agreement between the measured and predicted stresses during solidification in the presence of sufficiently large tensile strains. This was also noted as a shortcoming of a stress model for semisolid mush by Mathier and co-workers. ${ }^{[9,10]}$ As opposed to the volumetric damage considered in the present model, fracture of the mush is a highly localized process, similar to crack formation in fully solid materials. In the absence of liquid feeding, fracture of the mush naturally leads to the formation of an open hot tear.

After solidification is complete, the measured stresses in the experiments with hot tears increase with decreasing temperature at the same rate as in the experiments without hot tears. This indicates that the hot tears do not propagate significantly after solidification; i.e., they do not develop into hot cracks. Note in Figure 11(c) that the measured stress does not increase significantly until the temperature at the sprue-rod junction reaches the eutectic temperature of $710 \mathrm{~K}\left(437^{\circ} \mathrm{C}\right)$. This is somewhat surprising, since for the $\mathrm{Mg}-1$ wt pet $\mathrm{Al}$ alloy, no eutectic is expected to form. The formation of eutectic in this experiment can be explained by solute-rich liquid flowing toward the sprue-rod junction to compensate for the volume change due to damage of the mush. The overall solute concentration increases to the point that the last liquid to solidify is of the eutectic composition. Improving this modeling aspect requires not only the calculation of the liquid flow due to damage of the mush, but also taking into account the effect of the changing alloy composition on the solid fraction evolution.

\section{CONCLUSIONS}

An advanced stress model, including a viscoplastic constitutive model for a compressible semisolid mush, was used to predict forces measured during solidification and cooling of constrained rod-shaped castings of $\mathrm{Mg}$ alloys containing 1 and $9 \mathrm{wt}$ pct Al. Some of the mechanical properties needed in the stress model were estimated from data available in the literature. Force measurements from castings that did not hot tear were used to estimate the variation of the initial yield stress above $573 \mathrm{~K}\left(300{ }^{\circ} \mathrm{C}\right)$. Using these properties, good agreement between measured and predicted stresses was obtained for the experiments that did not exhibit hot tears. The stress variation during solidification was reasonably well predicted, although some improvements in the model for the onset of thermal contractions and the coherency properties of the semisolid mush are needed. Nonetheless, the present model and property data should prove valuable for simulating stresses and deformations of $\mathrm{Mg}-\mathrm{Al}$ alloy castings. The comparison of measured and predicted stresses for the experiments where hot tears were observed revealed that volumetric damage of the mush alone is not sufficient to explain the loss of coherency and strength of the mush under large tensile strains. A fracture model is needed to predict the reduction of the stresses due to the formation of tears within the mush. When coupled with calculations of the feeding flow, such a fracture model will naturally lead to the prediction of open hot tears. The present measurements also show that coupling of the stress model to a macrosegregation model, ${ }^{[1]}$ including full consideration of back-diffusion and the dependency of the solid fraction on composition, is needed to accurately predict stresses in the presence of hot tearing. The experimental data presented here should be valuable for validating such coupled models.

\section{ACKNOWLEDGMENTS}

This work was supported, in part, under the High Integrity Magnesium Cast Components (HIMAC) project sponsored by the United States Department of Energy under Award No. DE-FC26-02OR22910.

\section{REFERENCES}

1. M. M'Hamdi, A. Mo, and C. Martin: Metall. Mater. Trans. A, 2002, vol. 33A, pp. 2081-93. 
2. V. Mathier, J.M. Drezet, and M. Rappaz: Modell. Simul. Mater. Sci. Eng., 2007, vol. 15, pp. 121-34.

3. C.A. Monroe: Ph.D. Thesis, University of Iowa, Iowa City, IA, 2008.

4. M. Pokorny, C. Monroe, C. Beckermann, L. Bichler, and C. Ravindran: Int. J. Metalcasting, 2008, vol. 2, pp. 41-53.

5. C.A. Monroe, C. Beckermann, and J. Klinkhammer: in Modeling of Casting, Welding, and Advanced Solidification Processes-XII, S.L. Cockcroft and D.M. Maijer, eds., TMS, Warrendale, PA, 2009, pp. 313-20.

6. O. Ludwig, J.-M. Drezet, C.L. Martin, and M. Suery: Metall. Mater. Trans. A, 2005, vol. 36A, pp. 1525-35.

7. D.G. Eskin, Suyitno, and L. Katgerman: Prog. Mater. Sci., 2004, vol. 49, pp. 629-711.

8. A. Stangeland, A. Mo, O. Nielsen, D. Eskin, and M. M'Hamdi: Metall. Mater. Trans. A, 2004, vol. 35A, pp. 2903-15.

9. V. Mathier, P.D. Grasso, and M. Rappaz: Metall. Mater. Trans. A, 2008, vol. 39A, pp. 1399-1409.

10. V. Mathier, S. Vernede, P. Jarry, and M. Rappaz: Metall. Mater. Trans. A, 2009, vol. 40A, pp. 943-57.

11. K. Hu, A.B. Phillion, D.M. Maijer, and S.L. Cockcroft: Scripta Mater., 2009, vol. 60, pp. 427-30.
12. R.W. Fenn and J.A. Gusack: ASTM Proc., 1958, vol. 58, p. 685.

13. R.S. Busk: Magnesium Products Design, Marcel Dekker Inc., New York, NY, 1987.

14. C.H. Caceres, C.J. Davidson, J.R. Griffiths, and C.L. Newton: Mater. Sci. Eng. A, 2002, vol. 325, pp. 344-55.

15. F. Khomamizadeh, B. Nami, and S. Khoshkooei: Metall. Mater. Trans. A, 2005, vol. 36A, pp. 3489-94.

16. M. Mabuchi, M. Kobata, Y. Chino, and H. Iwasaki: Mater. Trans., 2003, vol. 44, pp. 436-39.

17. H. Cao and M. Wessen: Metall. Mater. Trans. A, 2004, vol. 35A, pp. 309-19.

18. K. Ishikawa, H. Watanabe, and T. Mukai: Mater. Lett., 2005, vol. 59, pp. 1511-15.

19. C.D. Lee and K.S. Shin: Acta Mater., 2007, vol. 55, pp. 4293-03.

20. M.C. Zhao, M. Liu, G.L. Song, and A. Atrens: Adv. Eng. Mater., 2008, vol. 10, pp. 93-103.

21. MAGMAsoft v.4.5, MAGMA GmbH, Aachen, Germany.

22. JMatPro v.4.0, Sente Software Ltd., Surrey, United Kingdom.

23. A.P. Roberts and E.J. Garboczi: J. Am. Ceram. Soc., 2000, vol. 83, pp. 3041-48.

24. A.C.F. Cocks: J. Mech. Phys. Solids, 1989, vol. 37, pp. 693715 . 